\title{
TOURNIQUETS IN FOREFOOT SURGERY
}

\author{
LESS PAIN WHEN PLACED AT THE ANKLE
}

VILHJALMUR FINSEN, ANN-MARI KASSETH

From the Trondheim University Hospital, Norway

We studied perioperative pain and postoperative neurological changes after surgery for hallux valgus in 50 patients operated on under local ankle block. Patients were randomised to have the pneumatic tourniquet either at calf level or just above the ankle. The cuffs were inflated to $100 \mathrm{mmHg}$ above systolic blood pressure. One patient was withdrawn from the study after randomisation. Areas of pain, paraesthesia and numbness were marked by patients on a diagram of the foot before operation and at six and ten weeks after operation.

Both positions of the tourniquet gave an excellent bloodless field. The proximal tourniquet gave significantly greater discomfort $(p<0.01)$ during the operation, after 10, 20 and 30 minutes. Application of the cuff at the ankle gave no relative increase in areas of numbness and paraesthesia at six and ten weeks.

An ankle tourniquet gives less discomfort with no increase in the incidence of nerve injury.

J Bone Joint Surg [Br] 1997;79-B:99-101.

Received 5 July 1996; Accepted after revision 26 August 1996

We perform almost all forefoot operations in adults on an outpatient basis using either local anaesthesia, or more often, an ankle block. At first, we placed a tourniquet at mid-calf level, ${ }^{1,2}$ but later placed it just above the ankle. We found that this reduced the levels of discomfort and did not observe any neurological or other complications.

We now report a prospective, randomised study of forefoot surgery to compare pain and neurological complica-

V. Finsen, PhD, Professor of Orthopaedic Surgery

A-M. Kasseth, SRN, Operating Theatre Nurse

Trondheim University Hospital, 7006 Trondheim, Norway.

Correspondence should be sent to Professor V. Finsen

C)1997 British Editorial Society of Bone and Joint Surgery 0301-620X/97/17069\$2.00 tions between pneumatic tourniquets placed either at calf level or just above the ankle.

\section{PATIENTS AND METHODS}

We included 50 consecutive patients who were to have outpatient surgery for hallux valgus. They all gave informed consent; permission for the study had been obtained from our local medical ethical committee. One patient was withdrawn by the operating surgeon after randomisation.

The remaining five men and 44 women had a mean age of 49 years (17 to 78). Two patients had McBride procedures, one a simple bunionectomy and medial capsule plication, and one a proximal metatarsal osteotomy combined with a McBride procedure. ${ }^{3}$ The other 45 had Mitchell osteotomies. ${ }^{3}$ Four patients also had resection of a second hammertoe. The mean duration of the operation was 35 minutes (12 to 70 ).

No premedication was used, and all the patients had a lignocaine block of the medial and anterior nerves at the ankle. ${ }^{4}$ We injected 5 to $10 \mathrm{ml}$ of lignocaine $(1 \%$ or $2 \%)$ behind the medial malleolus. A subcutaneous ridge of lignocaine was then injected on the front of the ankle from malleolus to malleolus and 2 to $3 \mathrm{ml}$ just lateral to the tendon of the extensor hallucis longus. The block was supplemented when necessary by local infiltration anaesthesia in 25 patients.

We used visual analogue scales (VAS) for subjective evaluation; the results were converted to a points scale on which 0 denoted no pain, or best imaginable result, and 100 the worst imaginable pain or result. The VAS score for pain was recorded every ten minutes during the operation and at three minutes after release of the tourniquet. Postoperatively, the operating surgeon gave a VAS evaluation of the quality of the anaesthesia and the bloodless field.

The patients were asked to mark areas of pain, numbness and paraesthesia on diagrams of the front and back of the foot before operation and at six and ten weeks postoperatively (Fig. 1).

Random numbers were used to allocate patients for the use of either an $11 \mathrm{~cm}$ wide tourniquet cuff on the calf (high position) or $9 \mathrm{~cm}$ wide cuff just above the ankle (low position) (Fig. 2). The cuffs were inflated to $100 \mathrm{mmHg}$ 

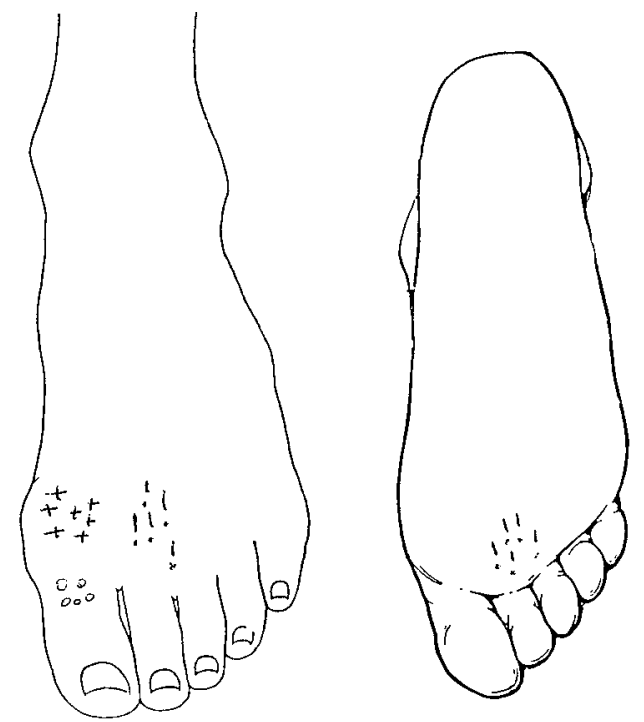

Fig. 1

Pain drawing of foot $(!=$ pain; $0=$ numbness; $+=$ paraesthesia).

Table I. Mean $( \pm$ SD) visual analogue scale (VAS) evaluation $(0=$ best imaginable; $100=$ worst imaginable) in the two groups

\begin{tabular}{lll}
\hline & $\begin{array}{l}\text { High group } \\
(\mathbf{n}=\mathbf{2 4})\end{array}$ & $\begin{array}{l}\text { Low group } \\
(\mathbf{n = 2 5 )}\end{array}$ \\
\hline Bloodless field & $3 \pm 7$ & $3 \pm 8$ \\
Anaesthesia & $4 \pm 8$ & $2 \pm 4$ \\
At tourniquet removal & $7 \pm 10$ & $5 \pm 7$ \\
\hline
\end{tabular}

above the systolic blood pressure.

Wilcoxon non-parametric tests were used for statistical evaluation and $\mathrm{p}$ values below 0.05 were considered significant.

\section{RESULTS}

The mean tourniquet pressures were almost identical in the two groups; $248 \mathrm{mmHg}$ in the high group and 247 in the low group. Both positions of the tourniquet were rated by the operating surgeons as giving an excellent bloodless field and did not affect their VAS evaluation of the anaesthesia (Table I).

The patients gave a significantly lower VAS score for pain during the operation at 10,20 and 30 minutes when the tourniquet was placed at the ankle $(\mathrm{p}<0.01)$ (Fig. 3). This difference was even greater at 40 and 50 minutes, but few operations lasted this long so the difference in results was not statistically significant. There was little pain in either group after the removal of the tourniquet (Table I).

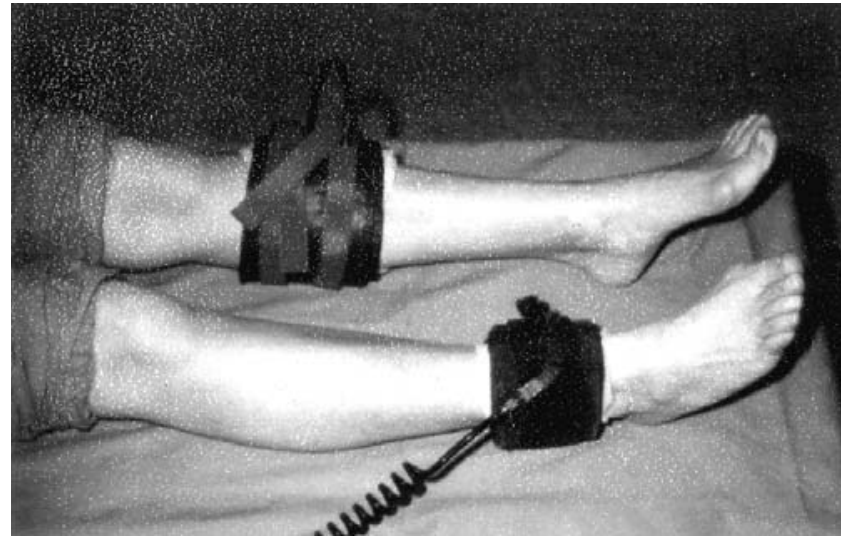

Fig. 2

Photograph showing the proximal and distal positions of the cuff.

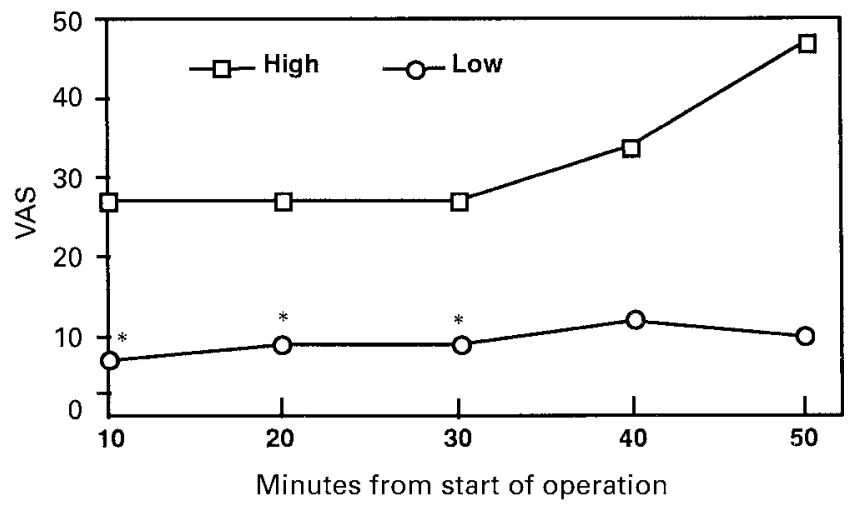

Fig. 3

Mean visual analogue score for pain during operation in high (proximal) and low (distal) tourniquet cuff placement $(*=\mathrm{p}<0.01)$.

Preoperative pain drawings showed areas of numbness and tingling in some patients. The number with these symptoms had increased at six weeks after operation, but when patients with symptoms in the big toe only were excluded, we found that the new appearance of these complaints had been recorded by only one of the 19 respondents in the low group and in none of the 21 respondents in the high group. At ten weeks, three of the 25 respondents in the low group and five of 24 respondents in the high group reported areas of altered sensation.

\section{DISCUSSION}

Because tourniquets are unphysiological and have given rise to repeated warnings of the dangers involved, there is continued apprehension with regard to nerve and muscle damage. When the commonly accepted pressures and durations of application are followed, danger is probably not as great as some perceive. Both nerve and muscle injury have been documented in animal studies, usually after very high 
pressures over a long time, ${ }^{5-8}$ there are relatively few reports of injuries to patients. Middleton and Varian ${ }^{9}$ considered that nerve injury was found in 1 in 5000 after a tourniquet was placed on the upper limb and 1 in 13000 for the lower limb. They also found that of 83 nerve injuries reported after an estimated 630000 tourniquet applications only two were permanent. There was only one reported muscle injury in their series.

It is often stated that the cuff should be placed in an area where the nerves are well protected by soft tissues. ${ }^{1,10}$ The reason for this is not clear. Tissue is incompressible so kinking or displacement of nerves is unlikely and would probably be more obvious when more soft tissues were included. In all but very thick limbs, tissue pressure has been found to increase by the same amount throughout any cross-section of a limb under tourniquet. ${ }^{11-13}$ Soft tissues do not and cannot protect the nerves against increased pressure.

Some surgeons use an Esmarch bandage as a tourniquet. This has rightly been condemned since it is impossible to determine the pressure exerted. ${ }^{10,14}$ This will depend on the force used in application and the number of turns of the bandage; tissue pressures of over $1000 \mathrm{mmHg}$ have been reported. ${ }^{9,12}$ All the palsies in the lower limb reported by Middleton and Varian ${ }^{9}$ were associated with the use of Esmarch bandages as tourniquets, although they had been used more rarely than pneumatic tourniquets.

There is no obvious reason why a pneumatic tourniquet cannot be used at the ankle and it may have certain advantages. The wider the cuff and the smaller the circumference of the limb, the lower is the cuff pressure needed to obtain a bloodless field. ${ }^{15-17}$ Graham et al ${ }^{18}$ found that with a cuff-width to limb-circumference ratio of 0.5 , the use of a subsystolic pressure was sufficient; at a ratio of 1.0 the required cuff pressure approached diastolic blood pressure. The leg just above the ankle is thin, and it is possible that a lower-than-normal cuff pressure may be adequate.

Outpatient operation using local or regional anaesthesia is becoming more frequent; more patients have a tourniquet placed proximal to the anaesthetised area. This is tolerated surprisingly well, but the procedure is distinctly uncomfortable. This discomfort should be reduced as much as possible without compromising the bloodless field or increasing the risk of complications. We found a significant reduction in pain when the tourniquet was placed at the ankle. It may be that less unanaesthetised tissue, particularly muscle, becomes ischaemic and that less muscle is compressed by the tourniquet.

Some patients reported areas of paraesthesia and numbness in the operated foot. The six-week pain drawings were usually made when plaster splinting was removed from the forefoot, which made it difficult for the patients to indicate their sensations accurately. The ten-week drawings were completed without supervision and returned by post, which made their accuracy uncertain. There were more apparent changes after calf than after ankle tourniquets, and no indication that the use of cuff at the ankle was more likely to lead to neurological damage.

After an upper limb tourniquet patients often complain of uncomfortable tingling for a few minutes after release. This can be painful, ${ }^{19}$ but was not seen in either of our lowerlimb groups.

We conclude that for surgery to the forefoot the pneumatic cuff of a tourniquet should be placed just above the ankle. This leads to significantly less pain than a more proximal site and the risk of neurological complications is not increased.

No benefits in any form have been received or will be received from a commercial party related directly or indirectly to the subject of this article.

\section{REFERENCES}

1. Adams JC. Standard orthopaedic operations. First ed, London: Churchill Livingstone, 1976:4-6.

2. Ferguson LK. Surgery of the ambulatory patient. Fourth ed, Philadelphia: Lippincott, 1966:71.

3. Mann RA. Duvries' surgery of the foot. Fifth ed. St Louis: Mosby, 1986:86-99.

4. Schurman DJ. Ankle-block anesthesia for foot surgery. Anesthesiology 1976;44:348-52.

5. Fowler TJ, Danta G, Gilliatt RW. Recovery of nerve conduction after a pneumatic tourniquet: observations on the hind-limb of the baboon. J Neurol Neurosurg Psychiatry 1972;35:638-47.

6. Ochoa J, Fowler TJ, Gilliatt RW. Anatomical changes in peripheral nerves compressed by a pneumatic tourniquet. J Anat 1972; 113:433-55.

7. Skjeldal S, Grøgaard B, Reikerås O, et al. Model for skeletal muscle ischaemia in rat hindlimb: evaluation of reperfusion and necrosis. Eur Surg Res 1991;23:355-65.

8. Pedowitz RA, Gershuni DH, Schmidt AH, et al. Muscle injury induced beneath and distal to a pneumatic tourniquet: a quantitative animal study of effects of tourniquet pressure and duration. $J$ Hand Surg [Am] 1991;16:610-21.

9. Middleton RWD, Varian JP. Tourniquet paralysis. Aust NZ J Surg 1974;44:124-8.

10. Fletcher IR, Healy TEJ. The arterial tourniquet. Ann $R$ Coll Surg Engl 1983;65:409-17.

11. Shaw JA, Murray DG. The relationship between tourniquet pressure and the underlying soft-tissue pressure in the thigh. J Bone Joint Surg [Am] 1982;64-A:1148-52.

12. McLaren AC, Rorabeck CH. The pressure distribution under tourniquets. J Bone Joint Surg [Am] 1985;67-A:433-8.

13. Graham B, Breault MJ, McEwen JA, McGraw RW. Perineural pressures under the pneumatic tourniquet in the upper extremity. $J$ Hand Surg [Br] \$O\$1992;17:262-6.

14. Klenerman L. Tourniquet paralysis. J Bone Joint Surg [Br] 1983; 65-B:374-5.

15. van Roekel HE, Thurston AJ. Tourniquet pressure: the effect of limb circumference and systolic blood pressure. J Hand Surg [Br] 1985; 10-B:142-4.

16. Moore MR, Garfin SR, Hargens AR. Wide tourniquets eliminate blood flow at low inflation pressures. J Hand Surg [Am] 1987; 12:1006-11.

17. Newman RJ, Muirhead A. A safe and effective low pressure tourniquet: a prospective evaluation. J Bone Joint Surg [Br] 1986;68-B: 625-8.

18. Graham B, Breault MJ, McEwen JA, McGraw RW. Occlusion of arterial flow in the extremities at subsystolic pressures through the use of wide tourniquet cuffs. Clin Orthop 1993;286:257-61.

19. Hutchinson DT, McClinton MA. Upper extremity tourniquet tolerance. J Hand Surg [Am] 1993;18:206-10. 